\title{
Fish Nutrition and Current Issues in Aquaculture: The Balance in Providing Safe and Nutritious Seafood, in an Environmentally Sustainable Manner
}

\section{Stefanie M Hixson*}

Department of Ocean Sciences, Memorial University of Newfoundland, St. John's, Newfoundland and Labrador, Canada

\begin{abstract}
Global aquaculture production has increased in recent years and it is predicted that aquaculture will provide the most reliable supply of seafood in the future. However, there are many controversial issues in aquaculture regarding food safety, nutrition, and sustainability; many of which are directly related to the nutrition and feeds for farmed fish. These nutrition-related issues must be considered in order to achieve balance in safe and nutritious food production and sustainability in aquaculture. This review highlights recent studies and discusses new and innovative aspects in fish nutrition. Some issues in the area of fish nutrition require consideration and improvement, such as: feed and nutrient efficiency, overfeeding and waste, fish meal and fish oil replacements, fish health, biotechnology, and human health concerns. The findings reviewed in this manuscript demonstrate promise toward improvement of the aquaculture industry through nutrition. This review is an update in fish nutrition research, and provides insight on the progression and evolution of this field in order to meet the needs of the industry with the purpose to achieve a balance in seafood production and environmental sustainability. The outcome of this review encourages the use of biotechnology as a tool to meet seafood production and environmental sustainability, in order to ensure global food security in the future and to improve our resource use.
\end{abstract}

Keywords: Aquaculture; Biotechnology; Feeds; Health; Nutrition; Sustainability

\section{Introduction}

Aquaculture requires optimisation of nutrition to efficiently raise fish for the purpose of food production. Fish nutrition is the study of nutrients and energy sources essential for fish health, growth and reproduction. Global consumption of seafood is increasing, while the amount of captured fish is declining, therefore it is predicted that aquaculture will provide the most reliable supply of seafood in the coming years. With the world's rapidly expanding population, it is important to provide safe and nutritious fish; however there are many issues related to fish nutrition that need to be considered in order to achieve balance in food production and sustainability. Sustainability of the aquaculture industry is an environmental, economic and social concern; however, this review focused specifically on environmental sustainability in regards to fish nutrition. Certain issues related to fish nutrition have become controversial because they impact the environment and/or affect the final product for consumption. Some of these issues include: feed and nutrient efficiency, overfeeding and waste, unsustainable feed ingredients, fish health issues, biotechnology and human health concerns. Ultimately, each of these issues can affect the final product for human consumption, either nutritionally, environmentally or economically. Achieving a balance between efficient and safe food production with environmental sustainability will be a challenge for the industry. The following is a review of several issues in farmed fish nutrition, relating to providing quality food products while maintaining environmental sustainability, emphasizing limitations of this balance and strategies for improvement.

\section{Fish nutrition and nutrient efficiency in aquaculture}

The essential nutrients for fish are amino acids, fatty acids, vitamins, minerals and energy-yielding macronutrients (protein, lipid and carbohydrate). Diets for fish must supply all essential nutrients and energy required to meet the physiological needs of growing animals. Guidelines for nutrient adequacy for some farmed fish species suggest the minimum nutrient requirement to promote growth and prevent signs of nutrient deficiency [1]. Protein is required in the diet to obtain amino acids, which are utilized to synthesize new proteins or maintain existing proteins in tissues while excess protein is converted to energy. Lipids supply essential fatty acids and energy in the diet. The requirement of essential fatty acids can only be met by supplying Long Chain (LC) Polyunsaturated Fatty Acids (PUFA) in the diet, specifically

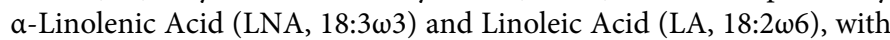
varying requirements for eicosapentaenoic acid (EPA, 20:5 133$)$ and docosahexaenoic acid (DHA, 22:6 33 ) depending on species. Dietary lipids are also important structural components of membranes, and act as precursors of steroid hormones and prostaglandins in fish. Dietary carbohydrates can be a source of energy for fish; however their ability to utilize dietary carbohydrate for energy varies depending on the species and their natural diet. Therefore, depending on species, protein and lipid are the main source of energy for fish. Feeds in aquaculture are formulated with a balance of nutrients in order to meet specific nutrient requirements for different species, life stages and other purposes.

The digestibility of nutrients in the feed can affect aquaculture production efficiency and impact the environment. The bioavailability or digestibility of the diet is the proportion of nutrients in the feed that is digested and absorbed by the fish. Data on the digestibility and available digestible energy of feed ingredients in fish diets are essential

*Corresponding author: Stefanie M Hixson, Department of Ocean Sciences Memorial University of Newfoundland, Marine Lab Road, St. John's, Newfoundland, Canada A1C 5S7, Tel: +1 709864 2521; E-mail: scolombo@mun.ca

Received March 24, 2014; Accepted May 05, 2014; Published May 15, 2014

Citation: Hixson SM (2014) Fish Nutrition and Current Issues in Aquaculture: The Balance in Providing Safe and Nutritious Seafood, in an Environmentally Sustainable Manner. J Aquac Res Development 5: 234 doi:10.4172/21559546.1000234

Copyright: (c) 2014 Hixson SM. This is an open-access article distributed under the terms of the Creative Commons Attribution License, which permits unrestricted use, distribution, and reproduction in any medium, provided the original author and source are credited. 
for optimization of feed formulations [1]. Feeds that are poorly digested result in limited growth and feces with high nutrient content, which pollutes the environment. Therefore, the digestibility of nutrients and the potential for nutrient retention and waste must be considered for efficient and sustainable animal production when considering feed formulations.

Growing fish accrete new tissues and some of the energy supplied in the diet is stored as protein, lipid and some glycogen. Protein deposition depends on the balance of available amino acids in protein and the digestible protein-to-digestible energy ratio. Excess energy intake and low protein levels result in the deposition of lipid as recovered energy, which does not equate to faster growth and is an inefficient use of nutrients. Fish have the ability to utilize lipids for energy, saving protein for deposition and growth [2]; therefore inclusion of lipids in diets for fish is important for both growth and energy purposes. Most commercial feeds today are formulated to increase growth performance by exploiting the protein-sparing effect of high energy lipid, allowing as much of the dietary protein as possible to be converted into muscle protein. As a result, the production efficiency of farmed salmon has significantly improved over time [3]. Today, the use of more highly digestible nutrient-density extruded feeds ( 46 to $50 \%$ protein, 20 to $24 \%$ fat) allows commercial farmers to achieve a Feed Conversion Ratio (FCR) of about 0.9-1.2 for rainbow trout (Oncorhynchus mykiss) grown to market size [2]. The improved FCR over time has been due to increased digestible nutrient and energy content of the feeds, as well as feed extrusion which has resulted in the production of feeds with higher lipid levels, improved starch gelatinization (increases digestible energy content and utilization), and improved pellet characteristics (durability, buoyancy, etc.) [2,3]. Further research to improve feed ingredients and feed efficiency in the future will help improve sustainability in aquaculture. For example, genetically modified (GM) salmon have better FCR than non-GM salmon (see Biotechnology section).

\section{Feeding and the environment}

Feed is the main source of waste and is responsible for most of the environmental impact of aquaculture [4] feed composition and the FCR affect the amount of waste produced, as well as its physical and chemical composition. Excess feed results in immediate eutrophication of the surrounding environment; while consumed feed is yields products of metabolic processes, such as ammonia, phosphorus and carbon dioxide [5]. The quantity and quality of the waste excreted by fish depend on intake, digestion and metabolism of dietary compounds [6]. Excess feed waste has a much greater capacity than fecal material to impact the environment, in terms of energy content and degradation rate. The particulate organic matter sinks and disperses, which results in environmental toxicity and anoxia [7]. The degree of impact from effluent wastes depends on feed quality, digestion and metabolism of the diet, species, culture method and the nature of the surrounding environment in terms of physics, chemistry and biology [8]. This has a direct impact on marine benthic habitats, with effects such as reducing sediments, hypoxia in the water overlying the sediment, increased sulphate reduction and changes in benthic fauna assemblages in terms of species number, diversity, abundance and biomass [7].

Feeding methods and technologies have advanced in recent years to minimize and eliminate waste, but the issue remains. Improved digestibility, feed utilization and feeding practices should implemented by the feed and production industry to reduce losses from waste. One example is the use of devices to monitor feeding activity from below the surface in order to feed to satiation without overfeeding and consequent feed wastage, a technology that has been used in recent years by several commercial farms [2]. Nutritional strategies to reduce waste include improvements in feed formulations without affecting growth and production efficiency, inclusion of feed ingredients with high phosphorus bioavailability, use of feed additives to improve the apparent digestibility of phosphorus, and processing-refining of ingredients [9]. These efforts have resulted in a significant reduction of waste outputs (per unit of fish produced) by fish culture operations in Canada over the past four decades [6]. However, feeds that are fully digested by the fish cannot totally resolve the impact of fecal waste because the scope of digestion in fish is limited and there will always be a fraction of undigested feed [10]. Removing the solid waste before it is discharged can be a solution for reducing the environmental impact of wastewater [9]. Eco-certification may be a tool to set standards with criteria aimed at reducing eutrophication through the level of inclusion; e.g., specific allowed amounts of nitrogen and phosphorus release from the system and a set limit for solids in the effluent water [11]. Integrated multi-trophic aquaculture (IMTA) of fish in combination with invertebrates and plants can help reduce environmental impacts and maximize the usage of food input. IMTA shows the most promise in terms of new and innovative systems for waste mitigation and production efficiency. The IMTA system reduces organic waste by mimicking trophic relationships found in nature; the waste from one organism is food for another, resulting in decreased organic particle concentrations with increased distance from farm sites as they are consumed by other farmed organisms [12]. The carbon, nitrogen, and phosphorus compositions of feed, fish and faeces were studied at an Atlantic salmon (Salmo salar) farm to estimate the release rates of wastes from salmon cages and the qualities of particulate wastes as food resources for integrated multi-trophic aquaculture. The study found that both salmon feed and faeces were adequate food for blue mussels (Mytilus edulis) and sea cucumbers (species unknown), and the nutrient content may meet their nutritional requirements, including DHA and EPA contents of feces, which were comparable to those of some phytoplankton species [13]. Other studies have also reported successful incorporation of nutrients from salmon waste feed into the tissue of blue mussels $[14,15]$. Choice of the extractive species and distance from the feeding location is an important consideration. For example, in a study on a commercial salmon farm in British Columbia, Canada, mussels had significantly higher amounts of DHA compared with other molluscs (chitons, clam, limpets, periwinkles and whelks), which indicates their potential in IMTA. The levels of DHA in mussels showed a significant breakpoint at $339 \mathrm{~m}$ from the farm, which suggests that distance should be considered to optimize certain nutrients [16]. However, organic fish waste captured by mussels is limited by the time available to intercept solid wastes contained in the horizontal particle flux, the velocity of the current, available IMTA farm space, and any negative feedback effects on fish culture from flow reduction caused by mussel culture [17]. New research is focused on expanding novel fish and extractive species. A study recently demonstrated that green sea urchins (Strongylocentrotus droebachiensis) actively ingest and absorb organic material from the waste produced by sablefish (Anoplopoma fimbria) culture. Further research was recommended to determine the effect of the sablefish waste diet on green sea urchin survivorship, growth, and gonad quality for urchin production [18]. Multi-species production in an IMTA system must be optimized and better utilized in the future to increase productivity and improve sustainability.

\section{Sustainable feeds and ingredients}

According to the Food and Agriculture Organization of the United Nations (FAO), at least half of the world's recognized fish stocks are 
fully exploited and $32 \%$ are overexploited or depleted [19]. With the production of farmed fish surpassing that of wild fish, aquaculture's share of global Fish Meal (FM) and Fish Oil (FO) consumption has more than doubled over the past decade [20]. For the past 25 years, annual FM and FO production has not increased beyond 1.5 million tons per year; therefore the aquaculture industry cannot continue to rely on finite stocks of marine pelagic fish as a supply of FM and FO [21]. The paradox of FM and FO use in aquaculture has sparked major research into alternative feed ingredients to replace FM and FO over the past two decades. The focus of this research has mainly been on terrestrial plant meals, concentrates and oils; and many of these studies have led to an impressive reduction in the average inclusion of FM and FO in commercial feeds [22]. The FAO predicts reductions in FM over the next decade for different fish diets: from $26 \%$ to $12 \%$ for marine fish, from $22 \%$ to $12 \%$ for salmon and from $3 \%$ to $1 \%$ for tilapia [3]. The FAO also predicts that the sustainability of the aquaculture industry will likely depend on using terrestrial plant oils for aquaculture feeds rather than solely depending on FO as a lipid source [19]. Other FM and FO alternatives include meat and bone meal, livestock tallow or fat, blood meal and poultry by-product meals; as well as fishery byproducts and zooplankton meals and oils [23]. Considering the use of alternative protein and lipid sources in commercial feeds [24], recent calculations using the Marine Nutrient Dependency Ratio (MNDR) estimate marine nutrient input to marine nutrient output ratios that are less than one; indicating that farmed salmon can be net producers of FM and FO [24]; and actually increases the supply of fish for human consumption by 7-8 million tonnes per year [25]. In fact, globally fed aquaculture is producing more than three times as much fish as it uses in the feed; therefore reducing the amount of FM and FO in the feeds actually increases the effective global supply of fish for human consumption. However, it is a challenge to find sustainable feed ingredients that meet the nutritional requirements of many farmed fish species. It is likely that some production of FM and FO will remain necessary due to nutritional and industry growth constraints.

Terrestrial plant meals and oils will probably continue to be the main choice when replacing FM and FO in aquaculture diets; however, they are fairly limited in their ability to fully replace FM and FO in diets for fish in terms of meeting nutritional requirements. As a protein source, plant meals are often deficient in certain essential amino acids, and contain high amounts of fibre, carbohydrate, and certain antinutritional factors, which cause adverse effects on feed intake, digestion, absorption, leading to reduced growth [26]. A meta-analysis by Collins et al. [27] found differences in the effect of plant ingredients on the growth performance of salmonid fish and that increasing the inclusion level of pea meal, pea protein concentrate, soy protein concentrate, canola/rapeseed meal or canola/rapeseed concentrate decreased the specific growth rate. The reduced growth performance can likely be explained by reduced protein, amino acid, lipid and energy digestibility, if not compensated by increased feed intake [27]. Some improvements in the nutritional quality can be achieved by chemical and mechanical processing, which can eliminate or reduce the concentration of certain anti-nutrients, as well as concentrate protein content [22]. In fact, in 25 years of research, fish growth performance in response to plant protein ingredients has improved due to changes in the chemical and physical properties of the ingredients due to advances in plant breeding, such as reducing the glucosinolate content in crops like canola [27]. Several studies have shown that replacing FO with various terrestrial plant oils in diets for different fish species does not compromise health, growth or feed consumption and are that they readily catabolised by fish as an energy source for growth, as reviewed by Turchini et al. [21]. However the fatty acid profile of terrestrial plant oils is not equivalent to that of FO, so research in this area has been extensive in recent years.

\section{Terrestrial plant oils in aquaculture feeds}

Terrestrial plant oils will likely be the main choice when replacing FO in aquaculture diets; however they are fairly limited in their ability to fully replace FO in diets for fish. Most plant oils are relatively poor sources of $\omega 3$ PUFA in comparison to marine FO, and completely lack LC $\omega 3$ PUFA. Rather, they are rich sources of $\omega 6$ and $\omega 9$ fatty acids, mainly LA and 18:1 $\omega 9$, with the exception of some oilseeds. Although considered an excellent energy source, feeding terrestrial plant oils inevitably results in lower levels of DHA and EPA in tissues of fish fed plant oils [21,28-32], which is detrimental to fish health and compromises the health benefits for humans that consume these fish. Extensive replacement of FO with terrestrial plant oils, particularly those high in LA, cause a high incidence of cardiovascular disorders in fish [33] and also has been suggested to be detrimental to human health after consumption of fish fed soybean oil [34], which is discussed in fish nutrition and human health section in this review. As a result, the immediate thought is that plant oils best suited as a substitute for FO should contain high levels of $\omega 3$ PUFA (LNA) and lower amounts of LA, in order to increase the $\omega 3 / \omega 6$ ratio. However, a study by Francis et al. [35] contradicts this idea because it was found that $\omega 6$ PUFA (sunflower oil diet) appeared to 'spare' the catabolism of $\omega 3$ LC PUFA and, as such, resulted in the highest retention of these fatty acids by rainbow trout. These results suggest new nutritional approaches to maximise the maintenance of the qualitative benefits of fish oils when they are used in feeds for aquaculture species [35]. Other recent studies have described that diets that contain high levels of LNA are relatively wasteful, because the fish did not extensively utilize the LNA toward $\omega 3$ PUFA biosynthesis, but rather catabolized the $\omega 3$ PUFA for energy. A similar observation is true for some fatty acid classes, particularly saturated fatty acids and monounsaturated fatty acids, which also appear to enhance the retention of $\omega 3$ LC PUFA in the fillets of some fish species. These observations have been found in Atlantic cod (Gadus morhua) [31], sunshine bass (Morone chrysops $x$ Morone saxatilis) [36], Murray cod (Maccullochella peelii peelii) [37] and rainbow trout [35]. This approach has been given the more specific definition of the ' $\omega 3 \mathrm{LC}$ PUFA sparing effect' as found in Atlantic salmon [36]. Consequently, it could be argued that plant oils high in LNA do not have any nutritional advantage over other commercially available oils with lower levels of $\omega 3$ PUFA, provided that DHA and EPA are spared through catabolism of other abundant fatty acids. These results also indicate that feeding a diet based on FO only is an inefficient practice anyway, because substantial amounts of the nutritionally valuable $\omega 3$ LC PUFA are oxidized for energy, particularly EPA [38]. Therefore, the use of plant oils in fish diets conserves LC $\omega 3$ PUFA in FO for critical physiological functions only. This has been the focus of studies in this area recently, specifically on the dynamics of dietary DHA/EPA/ARA and its effect on fish performance, tissue concentration and immunity (Table 1).

The ability of fish to synthesize LC PUFA may allow for plant oils to fully replace $\mathrm{FO}$ in aquaculture feeds without lowering levels of key fatty acids in the flesh such as DHA and EPA that are significant for fish and human health. The saturated fatty acids 16:0 and 18:0 can be biosynthesized by all known organisms, including fish. Desaturases and elongases are the critical enzymes in the pathways for the biosynthesis of the LC PUFA from the shorter-chain fatty acids to longer, more unsaturated chains. Fish can desaturate $16: 0$ and 18:0 to yield $16: 1 \omega 7$ and $18: 1 \omega 9$ by $\Delta 9$ desaturase. However, all vertebrates lack $\Delta 12$ and $\Delta 15$ desaturases, which are necessary to form LNA and LA, so these 
Citation: Hixson SM (2014) Fish Nutrition and Current Issues in Aquaculture: The Balance in Providing Safe and Nutritious Seafood, in an Environmentally Sustainable Manner. J Aquac Res Development 5: 234 doi:10.4172/2155-9546.1000234

Page 4 of 10

\begin{tabular}{|c|c|c|c|c|c|c|c|}
\hline Lipid source & Study duration (d) & Diet total lipid (\%) & $\omega 3 / \omega 6$ & EPA/ARA & DHA/EPA & $\mathbf{S G R}^{1}$ & Reference \\
\hline Tuna oil/rapeseed oil & 75 & 23.5 & 1.3 & 5 & 2.8 & 1 & Codabaccus et al. [38] \\
\hline Fish oil/chicken fat & 75 & 23.5 & 2 & 16 & 0.5 & 1 & Codabaccus et al. [38] \\
\hline Linseed oil & 112 & 20 & 3.6 & 4.9 & 1.8 & 2 & Francis et al. [35] \\
\hline Olive oil & 112 & 20 & 0.8 & 5.2 & 2.1 & 2 & Francis et al. [35] \\
\hline Palm oil & 112 & 20 & 0.8 & 5 & 2 & 2 & Francis et al. [35] \\
\hline Sunflower oil & 112 & 20 & 0.2 & 5 & 2.2 & 2 & Francis et al. [35] \\
\hline Fish oil/vegetable oil+EPA & 112 & 18 & 2.5 & 18 & 0.7 & - & Martinez-Rubio et al. [49] \\
\hline Fish oil+EPA & 112 & 18 & 3.6 & 18 & 0.9 & - & Martinez-Rubio et al. [49] \\
\hline Fish oil/rapeseed oil: high fat & 84 & 34 & 1.4 & 22 & 1.2 & 1.0 & Martinez-Rubio et al. [50] \\
\hline Fish oil/rapeseed oil: low fat & 84 & 20 & 1.5 & 26 & 1.3 & 0.9 & Martinez-Rubio et al. [50] \\
\hline Camelina oil & 112 & 19 & 1.2 & 15 & 1 & 0.9 & Hixson et al. [32] \\
\hline Olive oil+DHA & 62 & 20 & 1.3 & 4 & 19 & 1.2 & Glencross et al. [70] \\
\hline Olive+DHA+ARA & 62 & 18 & 0.5 & 0.1 & 6.8 & 1.2 & Glencross et al. [70] \\
\hline Rapeseed oil & 109 & 27 & 0.8 & 16 & 1.7 & 0.9 & Thomassen et al. [57] \\
\hline Rapeseed oil+EPA & 109 & 28 & 1.9 & 158 & 0.2 & 0.9 & Thomassen et al. [57] \\
\hline Rapeseed oil+EPA+DHA & 109 & 28 & 1.9 & 114 & 0.6 & 0.9 & Thomassen et al. 57] \\
\hline Rapeseed oil & 95 & 26 & 0.65 & 18 & 1.3 & 1 & Hatlen et al. [81] \\
\hline Rapeseed oil+GM yeast (high EPA source) & 95 & 23 & 0.8 & 33 & 0.3 & 0.9 & Hatlen et al. [81] \\
\hline Soybean oil+GM yeast (high EPA source) & 112 & 31 & 0.4 & 91 & z0.1 & 0.66 & Berge et al. [45] \\
\hline
\end{tabular}

${ }^{1}$ Specific growth rate, $\%$ day $^{-1}$

Table 1: Replacement of fish oil with terrestrial plant oils in diets for Atlantic salmon (Salmo salar), with particular focus on dietary DHA/EPA/ARA dynamics and the effect on tissue fatty acid composition and/or immune function.

fatty acids are considered essential. Subsequently, LNA and LA can be desaturated and elongated to form the physiologically essential EPA, DHA and ARA. However, the degree to which an animal can synthesize these fatty acids from LNA and LA depends on the activities of the elongase and desaturase enzymes $(\Delta 6$ and $\Delta 5)$ in their tissues. Fish species differ in the extent to which they can tolerate diets without FO, and this trait appears to be evolutionarily related to the fatty acid profile of the natural diet. Consequently, carnivorous marine fish have lost much of the capacity to synthesize these fatty acids during evolution since they remained in an environment where such a conversion is not necessary. Freshwater fish have a greater ability to biosynthesize EPA and DHA from LNA, since the natural prey of many freshwater fish is not rich in EPA and DHA, but rather LNA and LA. The fatty acid desaturation and elongation pathway has been extensively studied in fish at both the molecular and enzymatic level, with fatty acyl elongase (ELOVL) and fatty acyl desaturase (FAD) identified and functionally characterized in several marine and freshwater species. The dietary fatty acid profile is influential to the expression of ELOVL and FAD genes. The tissue fatty acid profile has been found to be significantly correlated with FAD and ELOVL gene expression in Atlantic cod fed diets without FO; while FAD and ELOVL expression were significantly correlated with each other [38]. This is evidence that the regulation of these genes is signalled by a change in the fatty acid profile of the tissue. However, up-regulation of these genes is not necessarily reflected phenotypically because levels of DHA and EPA in fish fed plant oil diets are significantly lower than DHA and EPA levels in fish fed a FO diet. However, these PUFA could be present in even lower amounts if ELOVL and FAD were not facilitating fatty acid biosynthesis. Often this effort cannot fully compensate for low levels of $\omega 3$ LC PUFA intake from plant oil diets; although results show that it is this low dietary level that may trigger the up-regulation of genes involved in their synthesis.

Using molecular tools to identify ELOVL and FAD gene expression has often been the centre of research studies on FO replacements. However, there are other tools that can be used to quantify LC PUFA biosynthesis and can verify phenotypically the results found at the gene expression level. Mathematically, the level of LC PUFA synthesis can be quantified using the fatty acid mass balance equation. The fatty acid mass balance method was developed for fish by Turchini et al. [40] to quantify $\omega 3$ fatty acid synthesis in fish to determine the level of elongation and desaturation that occurred over the course of a feeding experiment. The method involves computation of the fatty acid intake, accumulation, and appearance or disappearance of the selected fatty acids in the $\omega 3$ pathway and computes the percentage of synthesized $\omega 3$ LC PUFA from dietary intake of LNA. An application of this method revealed that Atlantic cod synthesized 6\% of their own LC $\omega 3$ PUFA [31], and $12 \%$ for rainbow trout [41] after fed a plant oil-based diet. Another interesting method to quantify LC PUFA biosynthesis is the use of compound specific stable isotope analysis. Fatty acid isotopic signatures are frequently used in food web studies to determine the transfer of fatty acids from prey to predator based on their $13 \mathrm{C} / 12 \mathrm{C}$ ratio [42]. Fatty acids from terrestrial plant oils have distinctly different isotopic signatures than the same fatty acids in marine sources like fish oil due to differences in the source of carbon (terrestrial carbon in the form of $\mathrm{CO}_{2}$ gas vs. marine carbon as carbonate) [43]. Using CSIA and a mixing model calculation [42], the proportion of synthesized LC PUFA (i.e., DHA) from LNA can be determined. Using this method it has been found that rainbow trout can synthesize up to $27 \%$ of the DHA in the muscle tissue from dietary camelina oil [31]. Quantifying fatty acid biosynthesis in fish using quick and efficient methods will become even more important in subsequent years; particularly if breeding programs are designed to select fish that have superior ELOVL and FAD expression and express these traits phenotypically.

Future research in this area will be dedicated to exploring new plant resources that have high levels of $\omega 3$ fatty acids, particularly plant sources that contain substantial levels of EPA and DHA. Single-celled microalgae and yeast can produce their own EPA and DHA and are renewable resources $[44,45]$; however, high production costs make commercialization very limiting. Research in this area is needed to optimize time and cost of production. However, the most promising and upcoming FO replacements are genetically modified LC $\omega 3$ PUFA enriched crop production [46,47] and is further discussed in the Biotechnology section of this review. The use of plant ingredients 
in aquaculture inevitable; however it also raises questions regarding sustainability of crop production for aquaculture feeds. Measurements to quantify the amounts of land, water, nutrients and energy required for crops per unit of fish production should be calculated to assess environmental impact and sustainable development, and also could be compared to other types of animal production. Nevertheless, the conservation benefit of substituting plant meal and oil for FM and FO is obvious.

\section{Fish nutrition and fish health}

It could be argued that the activity of intensive fish farming is, by definition, a stressful procedure, but such a consideration has to be balanced against the need to produce food for human consumption. Therefore, fish health is of upmost importance, in terms of an ethical and production point of view. Proper nutrition plays a critical role in maintaining normal growth and health of aquatic organisms. Good nutrition can help mitigate the effects of stress, decrease the susceptibility to disease, and boost the immune system; therefore it is important to consider their diet in terms of stress and disease prevention, while the diet may also serve as a primary method of administering medications, immuno-stimulants and functional ingredients for fish.

It is well established that all essential nutrients are required in sufficient quantity to sustain normal health. A deficiency in any required nutrient can adversely affect health by impairing metabolic functions and increasing susceptibility to disease. Lipids, for example, are directly involved in aspects of the immune response. LC PUFAs are precursors and modulators for eicosanoid production, including prostaglandins and thromboxane via a synthesis pathway involving cyclooxygenase

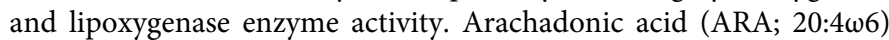
and EPA compete for the same lipoxygenase or cyclooxygenase, therefore the dietary $\omega 3 / \omega 6$ ratio determines the ratio of high activity (inflammation) to low activity eicosanoids (anti-inflammatory). Given the recent focus on FO replacements, studies have compared the immune and inflammatory response of fish fed different plant oil diets after infection by a virus or pathogen. For example, barramundi (Lates calcarifer) fed a diet with either FO or echium oil had a longer lasting and enduring response in eicosanoid concentrations following a week after bacterial infection, compared with those fed on rapeseed oil. Echium oil has a comparatively higher $\omega 3 / \omega 6$ ratio than rapeseed oil, and proved more effective in compensating for stress [48]. Another study tested functional feeds for Atlantic salmon infected with heart and skeletal muscle inflammation, an emerging viral disease caused by a novel salmon reovirus [49]. The functional feeds were formulated with reduced digestible energy levels achieved through lower lipid content, and specifically increased the EPA level and increased $\omega 3 /$ $\omega 6$ PUFA and EPA/ARA levels. The LC PUFA biosynthesis activity in salmon fed the standard diet was low compared to those fed the functional feed, limiting the availability of anti-inflammatory LC $\omega 3$ PUFA, which highlighted the crucial role of the diet in maintaining the availability of $\omega 3$ PUFA in membrane phospholipids. Both EPA and ARA reduced considerably after 16 weeks with infection; these losses were mitigated by the functional feed in comparison to those fed the standard feed, which likely contributed to the better outcome of fish fed the functional feed. In addition, reduced dietary lipid content altered the expression of key genes ( $\Delta 5$ and $\Delta 6$ FAD) in fish fed the functional feeds, potentially increasing their capacity for endogenous production and availability of anti-inflammatory EPA [49,50]. These results highlight the benefits of using diets with reduced dietary lipid and increased EPA levels on disease outcome. Factors that modulate and dampen the inflammatory process might be the key to mitigating clinical symptoms and improving performance, notably the $\omega 3 / \omega 6$ PUFA and EPA/ARA levels. Clinical nutrition through functional feeding has been shown to be an effective complementary therapy for emerging salmon viral diseases associated with long-term inflammation [49]. Therefore, future dietary formulations containing plant oil should consider the $\omega 3 / \omega 6$ ratio as it strongly affects eicosanoid production and can help deal with stress and disease; which has the focus of several recent studies related with fish oil replacements (Table 1).

Achieving good health through nutrition is relatively simple by providing essential nutrients in the right amount to cater to the specific requirements of different species and life stages. However, disease caused by infections and microorganisms is known to be one of the major constraints in the aquaculture industry, and fish may be susceptible to such diseases, regardless of nutritional status. Feeds containing antibiotics are commonly used to treat diseases. However, sick fish generally do not feed vigorously and therefore may not consume enough medicated feed to ensure proper dosage. The use of antibiotics in aquaculture is also problematic because of the potential to develop antibiotic resistant bacteria, the presence of antibiotic residues in seafood, destruction of microbial populations in the environment and suppression of the fish immune system $[51,52]$. Therefore, research has focused on functional constituents in feeds to improve growth, feed efficiency, health status, stress tolerance and resistance to disease to reduce antibiotic utilization in farms.

The concept of functional feeds is an emerging paradigm in the aquaculture industry, which are diets supplemented with feed additives to improve health and disease resistance with minimal negative effects on the fish, consumers and the environment [53]. Dietary supplementation of different non-digestible feed additives, such as immunostimulants, probiotics and prebiotics have been found to be beneficial for improving immune status, feed efficiency and growth performance in various different fish species. Feeding animals with immunostimulants prior to an infection or in situations known to result in stress will elevate defences and thus provide protection against otherwise potentially severe or lethal conditions [52]. Probiotics are live microbial organisms, non-pathogenic and non-toxic, which beneficially affect intestinal microbial products, reduce gut $\mathrm{pH}$ and release chemicals with bactericidal effects on other microbial populations, thus improving the immune response. The improvement in innate immunity in the fish helps against pathogenic bacteria, as well as against environmental stressors [54]. One of the major bottlenecks in the industry is high mortality during larval first feeding. Probiotics may be administered to live feed which act as live carriers of the bacteria and subsequently fed to fish larvae. This method has proven to be successful in European sea bass larvae (Dicentrarchus labrax) fed artemia cultured with bacterial enrichment, which affected the larval immune response and reduced mortality rates [55] Evidence of the beneficial effects of probiotics gave rise to the concept of prebiotics, which are indigestible oligosaccharides and dietary fibre that selectively stimulate growth and/or activate the metabolism of health-promoting bacteria in the gut, and depress the proliferation of harmful microbes, thus improving intestinal balance in the fish [51]. Beta-glucan for example, can act as both an immunostimulant and a prebiotic. It is a polysaccharide with glucose as its only structural component and forms the major constituents of the cell wall of some plants, fungi, bacteria, mushrooms, yeast, and seaweeds. Beta glucan appears to be the most promising feed additive to enhance growth, survival and immunity for a several different of farmed fish species, supplemented at levels between 0.1 to $1.0 \%$ (Table 2). Functional feed additives, such as beta glucan, can improve immunity, feed efficiency and growth performance of farmed 
Citation: Hixson SM (2014) Fish Nutrition and Current Issues in Aquaculture: The Balance in Providing Safe and Nutritious Seafood, in an Environmentally Sustainable Manner. J Aquac Res Development 5: 234 doi:10.4172/2155-9546.1000234

Page 6 of 10

\begin{tabular}{|c|c|c|c|c|}
\hline Compound & Species & Inclusion & Result & Reference \\
\hline Immunogen $^{\circledast}$ & $\begin{array}{l}\text { Rainbow trout } \\
\text { (Oncorhynchus } \\
\text { mykiss) }\end{array}$ & $0.2 \%$ & $\begin{array}{l}\text { Up-regulated immune related genes (lysozyme, TNFa), lower heat shock protein } \\
\text { (Hsp70) gene expression, stimulated humeral immune response, elevated } \\
\text { disease resistance }\end{array}$ & Ahmadi et al. [80] \\
\hline $\begin{array}{l}\text { Brown algae beta glucan } \\
\text { Laminaria digitata }\end{array}$ & Rainbow trout & $0.2 \%$ & $\begin{array}{l}\text { Increase in phagocytic activity in head kidney macrophages and a significant } \\
\text { increase in the production of TNFa and IL-8 in gill tissue }\end{array}$ & Morales-Lange et al. [89] \\
\hline $\begin{array}{l}\text { Yeast beta glucan } \\
\text { Saccharomyces cervisiae }\end{array}$ & & $0.2-0.4 \%$ & Increased compliment and immunoglobulin & Rozita et al [91] \\
\hline $\begin{array}{l}\text { Yeast beta glucan } \\
\left(\text { Aquate }{ }^{\circledR}\right)\end{array}$ & & $0.2 \%$ & $\begin{array}{l}\text { Successfully induced inflammatory gene expression (interleukin- } 1 \beta \text { ) in the head } \\
\text { kidneys of fish infected with Lepeophtheirus salmonis; lice burdens were lower } \\
\text { on fish fed Aquate }{ }^{\circledR}(19 \%)\end{array}$ & Poley et al [90] \\
\hline Yeast-derived beta glucan & & $0.1 \%$ & Up-regulation of IL-1 $\beta$ after challenged with Vibrio anguillarum & Lokesh et al. [88] \\
\hline Beta glucan & & $0.1 \%$ & $\begin{array}{l}\text { Significantly increased growth, antioxidant activity, and digestive enzyme activity } \\
\text { after exposure to lipopolysaccharides }\end{array}$ & $\begin{array}{l}\text { Guzman-Villanueva } \\
\text { et al. [89] }\end{array}$ \\
\hline $\begin{array}{l}\text { Oyster mushroom beta } \\
\text { glucan Pleurotus ostreatus }\end{array}$ & & $0.5-2.0 \%$ & $\begin{array}{l}\text { Significant shifts in white blood cell, lymphocyte, monocyte, neutrophil } \\
\text { granulocytes-segments, as well as plasma concentrations of glucose, albumins, } \\
\text { cholesterol, antrium and chlorides }\end{array}$ & Dobsikova et al. [84] \\
\hline Macro Gard ${ }^{\circledR}$ & & $1 \%$ & $\begin{array}{l}\text { Differentiated the regulation of mRNA expression of claudin genes and prevented } \\
\text { an intestinal inflammatory response post Aeromonas hydrophil intubation }\end{array}$ & Syakuri et al. [93] \\
\hline Macro Gard ${ }^{\circledR}$ & & $1-2 \%$ & $\begin{array}{l}\text { Fish fed diets containing } 1 \% \text { and } 2 \% \text { MacroGard }{ }^{\circledast} \text { showed significant } \\
\text { improvements in weight gain, specific growth rate and feed conversion ratio } \\
\text { compared to fish fed both the control and the } 0.1 \% \text { MacroGard }{ }^{\circledR} \text { containing diet }\end{array}$ & Kuhlwein et al. [87] \\
\hline $\begin{array}{l}\text { Mushroom beta glucan } \\
\text { Ganoderma lucidum and } \\
\text { Coriolus versicolor }\end{array}$ & & $0.2 \%$ & $\begin{array}{l}\text { Enhanced the lysozyme activity, alternative complement activity, phagocytic } \\
\text { activity and respiration burst; significantly enhanced the protection of grouper } \\
\text { against Vibrio alginolyticus up to } 16 \% \text { compared to control group }\end{array}$ & Chang et al. [82] \\
\hline Macrogard $^{\circledR}$ & & $0.1 \%$ & $\begin{array}{l}\text { Significantly reduced mortalities after challenging with Aeromonas hydrophila } \\
\text { with significant improvement in red blood corpuscles, white blood corpuscles, } \\
\text { pack cell volume, haemoglobin concentration, erythrocyte sedimentation rate and } \\
\text { serum protein content in treated groups over the control }\end{array}$ & Talpur et al. [94] \\
\hline
\end{tabular}

Table 2: Various forms of beta-glucan in functional feeds found to improve fish health and immunity for different farmed fish species.

fish [2] with minimal impact on the environment and the consumer; therefore commercial feeds may standardize its use in feeds.

\section{Biotechnology to improve fish nutrition}

Bridging the gap between problems and solutions in aquaculture will require insight and creative applications. Biotechnology research and applications can help the aquaculture industry develop sustainably, and efficiently produce good quality food for a growing human population. There are many new applications of biotechnology in aquaculture; however this review will focus on how biotechnology can improve fish nutrition for the purpose of safe, nutritious and sustainable food production. In particular, genetic modification will have the most significant impact on fish nutrition in aquaculture.

Producing environmentally sustainable and nutritionally sound feeds for farmed fish has proved to be a challenge. The application of biotechnology to produce feed ingredients that are specifically enhanced for aquaculture feeds can help alleviate pressure on wild fisheries that produce FM and FO. Research on GM crops that are enhanced specifically for fish feeds is in the forefront of both plant and aquaculture research. The limiting factor in using plant oils is the lack of LC $\omega 3$ PUFA, namely DHA and EPA. GM plants that can produce their own DHA and EPA, and that can be grown sustainably, is certainly well sought after by the aquaculture industry. Development of such a crop is in the research and development phase, but is not yet available commercially. A study by Ruiz-Lopez et al. [56] demonstrated fish oil-like levels of DHA and EPA produced by the transgenic oilseed camelina, while avoiding accumulation of undesirable fatty acids. Atlantic salmon fed GM rapeseed oil and yeast containing high levels of DHA and EPA showed high retention of LC $\omega 3$ PUFA in the flesh $[45,57]$. The benefits of producing LC $\omega 3$ PUFA in plants are clear: a sustainable and non-contaminated source of important fatty acids essential to human nutrition. GM crops may also have other enhanced features that can directly benefit aquaculture production, such as improving feed efficiency, performance, product quality and health; and can indirectly benefit production, such as pest and disease resistance, and increased yield [58].

A controversial and interesting topic of discussion is GM salmon. Aqua Bounty Technologies was the first company to submit an application to the Food and Drug Administration (FDA) for a GM animal for food consumption in 1995 and has been in the regulation system to date. In order to acquire FDA approval, Aqua Bounty has had to demonstrate the food's safety, and gauge the environmental risk of the sterile fish escaping its tanks and successfully breeding with wild salmon. By contrast, the FDA approved the first GM crop for human consumption (the Flavr Savr tomato) after just three years of regulatory consideration [59]. Research has shown that growth enhanced transgenic Atlantic and coho salmon (Oncorhynchus kisutch), have the capacity for increased daily feed intake, increased growth rates and improved feed utilization due to an enhanced capacity for protein biosynthesis over non-transgenic fish $[60,61,62]$. Transgenic coho salmon demonstrate an enhanced ability to utilize dietary carbohydrates (in addition to lipid) as a major source of non-protein energy, which is not typical for non-transgenic salmon [63]. The utilization of carbohydrate allows for greater amount of dietary protein to be spared for rapid tissue growth [62]. The altered gene expression and different metabolic enzyme capacity in transgenic salmon allows for a shift towards the use of fatty acids and glucose for energy-production purposes, conserving amino acids for protein biosynthesis [64]. In a study by Tibbetts et al. [62], transgenic Atlantic salmon consumed a significantly higher amount of feed on a daily basis, but also had better FCRs, higher nitrogen retention efficiency and achieved target weight gain in a shorter period (40\%) than non-transgenic fish. The transgenic salmon in this study demonstrated a higher cellular capacity to direct dietary non-protein energy towards satisfying their daily metabolic energy requirements, allowing for a higher proportion of dietary amino acids to be directed towards protein biosynthesis rather than catabolised as a dietary 
energy source. Dietary protein represents the highest proportion of salmon feeds and also the major source of nitrogenous pollution from salmon farming; therefore transgenic salmon could improve production efficiency through better feed utilization, which could result in more sustainable salmon production. Furthermore, transgenic salmon were found to have a higher expression of $\Delta 5$ and $\Delta 6 \mathrm{FAD}$, which might help compensate for a potentially higher demand for EPA and DHA resulting from rapid growth [64]. This also has positive implications for the use of alternative FO feeds for transgenic fish in terms of their ability to synthesize EPA and DHA at an increased rate. However, there are environmental concerns related to GM salmon, particularly the potential impacts of escaped GM salmon on wild salmon; although GM salmon produced by Aqua Bounty are sterile, thus eliminating the potential of interbreeding between escaped GM salmon and wild salmon. There are also health and safety concerns that pertain to the immediate and long-term effects on human health after consumption of GM salmon products. Initial tests on the safety of consuming transgenic carp and tilapia show no apparent negative health impacts on mice and humans [65]. However, allergens or toxins may be produced as a result of gene transfer if the transgene codes for a protein that induces expression of a previously inactive toxin (e.g., shellfish protein used to create a transgenic fish), and the expression of bioactive proteins which may continue to possess bioactive properties following consumption (e.g., growth hormone) [65]. Research on the effect of GM fish on human health should be conducted, as well as the effect on product quality.

\section{Fish nutrition and human health}

The world will be very different in 2050: the global population will likely increase to nine billion, and about $50 \%$ more food will be needed to sustain the quality of human life [66]. Rapid population growth and increases in fish consumption has led to rapid increases in global fish demand. The expansion of aquaculture will fill this gap and relieve pressure on capture fisheries, which have been steadily declining [67]. The benefits of consuming a diet rich in seafood are based on high levels of LC $\omega 3$ PUFA and high quality animal protein, essential amino acids, vitamins, and minerals [67]. There are numerous benefits of aquaculture being the main supply of seafood for the world, from a nutritional, economic and social standpoint; however the industry has received much public scrutiny regarding toxins, contaminants, hormones, and antibiotics in farmed fish, which raises questions about public health and safety [68].The composition of the feed affects the final composition of the product; therefore fish nutrition directly impacts consumers and must be considered in terms of safety and human nutrition.

It is obvious that the use of FM and FO must be significantly reduced in aquaculture feeds in order to be environmentally sustainable. However, using sustainable alternative feed ingredients to feed fish could potentially affect human health. For example, terrestrial plant oils are typically high in $\omega 6$ fatty acids, specifically LNA, which get stored in significant amounts in flesh of the fish that are consuming these feeds. From a human health standpoint, increases in $\omega 6$ fatty acids in salmon fillets are a concern. When mice were fed farmed salmon raised on diets with $100 \%$ soybean oil, the excessive dietary LA elevated endocannabinoids in the liver, increased weight gain and counteracted the anti-inflammatory properties of EPA and DHA [69] and also exaggerated insulin resistance and increased accumulation of fat in the liver in rats [34]. The typical "Western" diet is already dangerously high in $\omega 6$ fatty acids, which is why it is so important to consume fish that are high in $\omega 3$ fatty acids to balance this ratio. However, in addition to the high level of $\omega 6$ fatty acids, terrestrial plant oils do not contain EPA and DHA, which causes a lower concentration of these PUFA in farmed seafood products compared to farmed fish that were fed a FObased diet. Most consumers are not fully aware of the lower DHA and EPA content now occurring in many farmed fish species as a result of using alternative feeds in recent years. A study by Nichols et al. [70] investigated the LC $\omega 3$ PUFA content in farmed Atlantic salmon and barramundi samples from 2002 compared to samples from 2010-2013. In comparison to the 2002 samples, both species contained decreased levels and contents of LC $\omega 3$ PUFA. Atlantic salmon in 2002 contained $2014 \mathrm{mg} / 100 \mathrm{~g}$, decreasing to $975 \mathrm{mg} / 100 \mathrm{~g}$ in 2013. Barramundi in 2002 contained $1970 \mathrm{mg} / 100 \mathrm{~g}$, decreasing to $790 \mathrm{mg} / 100 \mathrm{~g}$ in 2013 [70]. These changes have resulted from the use of new, sustainable and lower cost ingredients in the feed. Despite significantly lower LC $\omega 3$ PUFA amounts in farmed salmon compared to a decade ago, a human study found that addition of farmed Atlantic salmon to the diet twice per week for 4 weeks at portions of $180 \mathrm{~g}$ and $270 \mathrm{~g}$ modifies phospholipid fatty acid proportions of $\omega 3$ and $\omega 6$ in a level associated with decreased risk for cardiovascular disorders [71]. Regardless, there are strategies to increase the $\omega 3$ PUFA content in the lipid profile of farmed fish. In the present time, even using plant oils that are high in LNA but do not supply DHA and EPA is still beneficial for humans simply to achieve a higher $\omega 3 / \omega 6$ ratio in the diet. Finishing oil diets with higher inclusion of marine oils at the end of the production cycle can elevate DHA and EPA levels immediately before harvest. This may result in grades of farmed seafood products that contain a higher content of LC $\omega 3$ PUFA than standard (and lower cost) products grown using a mainly nonmarine oil based diet [70]. In the future it is likely that GM plants with endogenous DHA and EPA will be used in fish feeds. The effect of GM foods on human health is not well known, however, many different types of produce and processed foods available today are non-labelled GM, so many North American consumers have purchased GM foods on a regular basis for at least a decade. However, there have been no studies to date on the long term effect of GM ingredients fed to farmed fish on human health. This will be a critical area of research in the future.

Dietary changes may also affect the product quality of the fish, which may change public perception of farmed fish. Sensory evaluations, including taste, colour and texture are frequently part of studies that evaluate changes after feed ingredients have been altered in the diet, particularly replacements of FM and FO. Although many studies have reported that alternative protein and lipid sources can affect the sensory quality of farmed fish, results in the literature are divided and contradictory [21], therefore it is difficult to pinpoint if certain ingredients clearly affect sensory quality because it can depend on the study. Interestingly, some studies showed that salmon fed plant oils had less rancid and marine characteristics and were preferred over salmon fed FO [72]. Consumer perception and satisfaction are an important aspect of fish nutrition; therefore the use of GM ingredients or the production of GM salmon needs to be evaluated for sensory quality due to possible biochemical changes that affect sensory characteristics.

Contamination of fish tissues with organic and inorganic contaminants has been a pervasive environmental and public health issue. From a human health perspective, concerns regarding relatively high levels of Persistent Organic Pollutants (POPs) (e.g. Polychlorinated Biphenyls, PCBs) and inorganic contaminants (e.g. heavy metals) in farmed salmon have raised questions regarding the relative health risks and benefits of farmed salmon consumption [73]. However, the accumulation of some contaminants is the result of indirect exposure, 
Citation: Hixson SM (2014) Fish Nutrition and Current Issues in Aquaculture: The Balance in Providing Safe and Nutritious Seafood, in an Environmentally Sustainable Manner. J Aquac Res Development 5: 234 doi:10.4172/2155-9546.1000234

Page 8 of 10

and can equally affect wild salmon [74]. This review will only focus on POPs accumulated in the flesh as a direct result of the feed. Fish that are fed FM and FO accumulate POPs that are derived from marine feed components, and several studies have reported elevated levels of environmental contaminants, particularly PCBs in feeds and farmed Atlantic salmon flesh [75]. One of the benefits of using plant meal and oil to replace FM and FO is the reduced levels of toxins in the feeds, and subsequently in the final product. Studies have shown that using plant oils to replace FO for most of the production cycle show large reductions in flesh POPs in salmon; thereby providing a low contaminant product for human consumption [75,76]. Interestingly, Atlantic salmon fed a diet that replaced $75 \%$ FO with flaxseed oil showed $61 \%$ lower levels of POPs in the flesh compared with fish fed diets with $100 \%$ FO, without compromising growth performance [77]. Farrell et al. [78] concluded that plant oils in salmon feeds considerably lower contaminant levels in farmed salmon without reducing the human health benefits and compromising production efficiency. Furthermore, rats that were fed farmed salmon raised on $100 \%$ soybean oil had significantly lower levels of POPs in their tissues compared to rats fed salmon raised on FO [34]. However, considering high levels of LA and significantly reduced levels of DHA and EPA in salmon after fed a plant oil diet, there is certainly a trade-off between using plant oils and marine oils. The best possible outcome to achieve environmental sustainability and reduce dependence on marine resources, while maximizing the amount of DHA and EPA in farmed seafood would be using GM oilseeds with equivalent levels of DHA and EPA to that of FO.

\section{Conclusion}

Fish nutrition certainly has an impact on the aquaculture industry. The areas discussed in this review were meant to highlight current issues in aquaculture related specifically to the nutrition of farmed fish and how these issues can impact food safety and quality, as well as environmental sustainability. In a world where natural resources are being consumed at 50 times the replenishment rate, the future belongs to those who can manage elements of population growth, climate change, and food and energy security. Aquaculture has a huge role to play in the future where safe, nutritious, quality food is in demand and environmental sustainability is the key to life [79]. It is difficult to quantify environmental impacts and sustainability in aquaculture since different species and production systems are more sustainable than others because of their feeds and feeding practices. The result is a trade-off of positive and negative outcomes, and both food security and sustainability must be balanced. The future advancements in aquaculture to achieve this balance will inevitably require the use of biotechnology. Scientists should be able to develop and effectively use new technologies, within reason, to benefit of our society. The use of GM plants and animals to increase nutrient utilization and production efficiency, and to reduce environmental impacts, will become necessary in the future. However, food safety is of upmost importance, therefore diligent research and stringent regulations must be required before commercialization of GM products. The balance between nutritious, safe food production and maintaining environmental sustainability will rely on our ability to use new technologies to improve farming practices, and our ability to use as few resources as possible to provide for our society [80-95].

\section{Acknowledgements}

This review was supported by the Research and Development Corporation of Newfoundland (RDC) and Memorial University of Newfoundland. The author would like to thank Dr. Christopher C. Parrish for review of this paper.

\section{References}

1. National Research Council (NRC) (2011) Nutritional requirements of fish and shrimp. National Acadamies Press, Washington.

2. Ganguly S, Krushna C, Sarkar S, Chowdhury S (2013) Supplementation of prebiotics in fish feed: a review. Rev Fish Biol Fisheries 23: 195-199.

3. Tacon A, Hasan M, Metian M (2011) Demand and supply of feed ingredients for farmed fish and curstaceans- trends and prospects. FAO fisheries technical paper, vol. 564.

4. d'Orbcastel E, Blancheton J, Aubin J (2009) Towards environmentally sustainable aquaculture : Comparison between two trout farming systems using life cycle assessment. Aquacult Eng 40: 113-119.

5. Schneider O, Amirkolaie A, Vera Cartas J, Eding E, Schrama J, et al. (2004) Digestibility, faeces recovery, and related $\mathrm{C}, \mathrm{N}, \mathrm{P}$ balances of five feed ingredients evaluated as fishmeal alternatives in Oreochromis niloticus $\mathrm{L}$. Aquaculture Research 35: 1370-1379.

6. Bureau D, Hua K (2010) Towards effective nutritional management of waste outputs in aquaculture, with particular reference to salmonid aquaculture operations. Aquacult Rev 41: 777-792.

7. Piedecausa M, Aguado-Gimenez F, Valverde J, Llorente M, Garcia-Garcia B (2012) Influence of fish food and faecal pellets on short-term oxygen uptake ammonium flux and acid volatile sulphide accumulation in sediments impacted by fish farming and non-impacted sediments. Aquacult Res 43: 66-74.

8. Boyd C, Tucker C, McNevin A, Bostick K, Clay J (2007) Indicators of resource use efficiency and environmental performance in fish and crustacean aquaculture. Rev Fish Sci 15: 327-360.

9. Amirkolaie A (2011) Reduction in the environmental impact of waste discharged by fish farms through feed and feeding. Rev Aqua 3:19-26.

10. Cho C, Hynes J, Wood K, Yoshida H (1994) Development of high-nutrientdense, low-pollution diets and prediction of aquaculture wastes using biological approaches. Aquaculture 124: 293-305.

11. Jonell M, Phillips M, Ronnback P, Troell M (2013) Eco-certification of farmed seafood: will it make a difference? AMBIO 42: 659-74.

12. Reid G, Liutkus M, Bennett A, Robinson S, MacDonald B, et al. (2010) Absorption efficiency of blue mussels (Mytilus edulis and M. trossulus) feeding on Atlantic salmon (Salmo salar) feed and fecal particulates: implications for integrated multi-trophic aquaculture. Aquaculture 299: 165-169.

13. Wang X, Andersen K, Handa A, Jense B, Reitan K, et al. (2013) Chemical composition and release rate of waste discharge from an Atlantic salmon farm with an evaluation of IMTA feasibility. Aquacult Env Interac 4: 147-162.

14. Handa A, Min H, Wang X, Broch O, Reitan K, et al. (2012) Incorporation of fish feed and growth of blue mussels (Mytilus edulis) in close proximity to salmon (Salmo salar) aquaculture: Implications for integrated multi-trophic aquaculture in Norwegian coastal waters. Aquaculture. 356: 328-341.

15. Redmond K, Magnesen T, Hansen P, Strand O, Sonnich M (2010) Stable isotopes and fatty acids as tracers of the assimilation of salmon fish feed in blue mussels (Mytilus edulis). Aquaculture. 298: 202-210.

16. George E, Parrish C (2013) Invertebrate uptake of lipids in the vicinity of Atlantic salmon (Salmo salar) aquaculture sites in British Columbia. Aquacult Res DOI: 10.1111/are.12259.

17. Cranford P, Reid G, Robinson S (2013) Open water integrated multi-trophic aquaculture: constraints on the effectiveness of mussels as an organic extractive component. Aquacult Env Interac 4: 163-173.

18. Orr L, Curtis D, Cross S, Gurney-Smith H, Shanks A, et al. (2014) Ingestion rate, absorption efficiency, oxygen consumption, and fecal production in green sea urchins (Strongylocentrotus droebachiensis) fed waste from sablefish (Anoplopoma fimbria) culture. Aquaculture 422: 184-192.

19. FAO (Food and Agricultural Organization of the United Nations) (2010) The state of the world fisheries and aquaculture 2010.

20. Naylor R, Hardy R, Bureau D, Chiu A, Elliott M, et al. (2009) Feeding aquaculture in an era of finite resources. PNAS 106: 15103-15110.

21. Turchini G, Torstensen B, Ng W (2009) Fish oil replacement in finfish nutrition Rev Aqua 1: 10-57. 
Citation: Hixson SM (2014) Fish Nutrition and Current Issues in Aquaculture: The Balance in Providing Safe and Nutritious Seafood, in an Environmentally Sustainable Manner. J Aquac Res Development 5: 234 doi:10.4172/2155-9546.1000234

Page 9 of 10

22. Olsen R, Hasan M (2012) A limited supply of fishmeal: Impact on future increases in global aquaculture production. Trends Food Sci Tech 27: 120-128.

23. Hertrampf J, Piedad-Pascual F (2000) Handbook on ingredients for aquaculture feeds. Kluwer Academic Publishers, Netherlands.

24. Crampton V, Nanton D, Ruohonen K, Skjervold P, El-Mowafi A (2010) Demonstration of salmon farming as a net producer of fish protein and oil. Aquacult Nutr 16: 437-446.

25. Jackson A (2012) Fish meal and fish oil and its role in sustainable aquaculture. International aquafeed 15: 18-21.

26. Krogdahl A, Penn M, Thorsen J, Refstie S, Bakke A (2010) Important antinutrients in plant feedstuffs for aquaculture: an update on recent findings regarding responses in salmonids. Aquacult Res 41: 333-344

27. Collins S, Overland M, Skrede A, Drew M (2013) Effect of plant protein sources on growth rate in salmonids: Meta-analysis of dietary inclusion of soybean, pea and canola/rapeseed meals and protein concentrates. Aquaculture 400: 85-100.

28. Bell G, Pratoomyot J, Strachan F, Henderson R, Fontanillas R, et al. (2010) Growth, flesh adiposity and fatty acid composition of Atlantic salmon (Salmo salar) families with contrasting flesh adiposity: Effects of replacement of dietary fish oil with vegetable oils. Aquaculture 306: 225-232.

29. Alhazzaa R, Bridle A, Nichols P, Carter C (2011) Replacing dietary fish oil with echium oil enriched barramundi with C18 PUFA rather than long-chain PUFA Aquaculture 312: 162-171.

30. Hixson S, Parrish C, Anderson D (2013) Effect of replacement of fish oil with camelina (Camelina sativa) oil on growth, lipid class and fatty acid composition of farmed juvenile Atlantic cod (Gadus morhua). Fish Physiol Biochem 39 $1441-1456$.

31. Hixson S, Parrish C, Anderson D (2014) Full substitution of fish oil with camelina oil, with partial substitution of fish meal with camelina meal, in diets for farmed Atlantic salmon (Salmo salar) and its effect on tissue lipids and sensory quality. Food Chem 157: 51-61.

32. Hixson S, Parrish C (2014) Substitution of fish oil with camelina oil and inclusion of camelina meal in diets of Atlantic cod (Gadus morhua) and its effect on growth and tissue lipid classes and fatty acids. J Anim Sci 92: 1055-67.

33. Waagbo $\mathrm{R}$ (2008) Reducing production related diseases in farmed fish. In: Lie O (ed) Improving Farmed Fish Quality and Safety. VS Woodhead Publishing, UK, pp 363-398.

34. Mitdbo L, Ibrahim M, Myrmel L, Aune U, Alvheim A, et al. (2013) Intake of farmed Atlantic salmon fed soybean oil increases insulin resistance and hepatic lipid accumulation in mice. PLOS One 8: 1-11.

35. Francis D, Thanuthong T, Senadheera S, Paolucci M, Coccia E, et al. (2014) n-3 LC-PUFA deposition efficiency and appetite-regulating hormones are modulated by the dietary lipid source during rainbow trout grow-out and finishing periods. Fish Physiol Biochem 40: 577-593.

36. Trushenski J (2009) Saturated lipid sources in feeds for sunshine bass: alterations in production performance and tissue fatty acid composition. North Am J Aquacult 71: 363-373.

37. Turchini G, Francis D, Senadheera S, Thanuthong T, De Silva S (2011) Fish oil replacement with different vegetable oils in Murray cod: Evidence of an "omega-3 sparing effect" by other dietary fatty acids. Aquaculture 315: 250-259.

38. Codabaccus B, Carter C, Bridle A, Nichols $P$ (2012) The "n-3 LC-PUFA sparing effect" of modified dietary n-3 LC-PUFA content and DHA to EPA ratio in Atlantic salmon smolt. Aquaculture 356: 135-140.

39. Xu X, Feng C, Hixson S, Johnstone K, Anderson D, et al. (2014) Characterization of fatty acyl elongase (elovl) gene family, and hepatic elovl and delta-6 fatty acyl desaturase (fadsd6) transcript expression and fatty acid responses to diets containing camelina oil in Atlantic cod (Gadus morhua). Comp. Biochem. Physiol. B. Accepted manuscript in press.

40. Turchini G, Francis D, De Silva S (2007) A whole body, in vivo, fatty acid balance method to quantify PUFA metabolism (desaturation, elongation and beta-oxidation). Lipids 42: 1065-1071.

41. Turchini G, Francis D (2009) Fatty acid metabolism (desaturation, elongation and b-oxidation) in rainbow trout fed fish oil- or linseed oil-based diets. $\mathrm{Br} \mathrm{J}$ Nutr 102: 69-81.

42. Budge S, Wooller M, Springer A, Iverson S, McRoy C, et al. (2008) Tracing carbon flow in an arctic marine food web using fatty acid stable isotope analysis. Oecologia 157: 117-129.

43. O'Leary M (1988) Carbon isotopes in photosynthesis. Bioscience 38:328-336.

44. Bendiksen E, Johnsen C, Olsen H, Jobling M (2011) Sustainable aquafeeds: Progress towards reduced reliance upon marine ingredients in diets for farmed Atlantic salmon (Salmo salar). Aquaculture 314: 132-139.

45. Hatlen B, Berge G, Odom J, Mundheim H, Ruyter B (2012) Growth performance feed utilisation and fatty acid deposition in Atlantic salmon, Salmo salar L., fed graded levels of high-lipid/high-EPA Yarrowia lipolytica biomass. Aquaculture 364: 39-47.

46. Napier J, Sayanova O (2005) The production of a very-long-chain PUFA biosynthesis in transgenic plants: towards a sustainable source of fish oils. Proc Nutr Soc 64: 387-393.

47. Flachowsky G, Meyer U, Gruen M (2013) Plant and animal breeding as starting points for sustainable agriculture. In: Lichtfouse $E$ (ed) Sustainable Agriculture Reviews 12. Springer, Netherlands, pp 201-224

48. Alhazzaa R, Bridle A, Mori T, Barden A, Nichols P, et al. (2013) Echium oil is better than rapeseed oil in improving the response of barramundi to a disease challenge. Food Chem 141: 1424-1432.

49. Martinez-Rubio L, Morais S, Evensen O, Wadsworth S, Vecino J, et al. (2013a) Effect of functional feeds on fatty acid and eicosanoid metabolism in liver and head kidney of Atlantic salmon (Salmo salar L.) with experimentally induced heart and skeletal muscle inflammation. Fish Shellfish Immunol 34: 1533-1545.

50. Martinez-Rubio L, Wadsworth S, Vecino J, Bell G, Tocher D (2013b) Effect of dietary digestible energy content on expression of genes of lipid metabolism and LC-PUFA biosynthesis in liver of Atlantic salmon (Salmo salar L.). Aquaculture 384: 94-103

51. Ringo E, Olsen R, Gifstad T, Dalmo R, Amlund H, et al. (2010) Prebiotics in aquaculture- a review. Aquacult Nutr 16: 117-136.

52. Oliva-Teles A (2012) Nutrition and health of aquaculture fish. J Fish Dis 35:83108

53. Meena D, Dad P, Kumar S, Mandal S, Prusty A, et al. (2013) Beta-glucan: an ideal immunostimulants in aquaculture (a review). Fish Physiol Biochem 39 431-457.

54. Mohapatra S, Chakraborty T, Prusty A, Das P, Paniprasad K, et al. (2012) Use of different microbial probiotics in the diet of rohu, Labeo rohita fingerlings: effects on growth, nutrient digestibility and retention, digestive enzyme activities and intestinal microflora. Aquacult Nutr 18: 1-11.

55. Franke A, Roth O, Clemmesen C (2013) Early stimulation of the immune system of an important aquaculture fish species: Probiotic application in European sea bass juveniles Fish \& Shellfish Immunol 34: 1707-1715

56. Ruiz-Lopez N, Haslam R, Napier J, Sayanova O (2014) Successful high-leve accumulation of fish oil omega-3 long-chain polyunsaturated fatty acids in a transgenic oilseed crop. The Plant J. 77: 198-208.

57. Thomassen M, Rein D, Berge G, Østbye T, Ruytera B (2012) High dietary EPA does not inhibit $\Delta 5$ and $\Delta 6$ desaturases in Atlantic salmon (Salmo salar L.) fed rapeseed oil diets. Aquaculture 361: 78-85.

58. Deb R, Sajianar B, Devi K, Reddy K, Prasad R, et al. (2013) Feeding animals with GM crops: Boon or bane? Indian J Biotech 12: 311-322.

59. Ledford H. (2013) Transgenic salmon nears approval. Nature 497: 17-18.

60. Devlin R, Biagi C, Yesaki T (2004) Growth, viability and genetic characteristics of $\mathrm{GH}$ transgenic coho salmon strains. Aquaculture 236:607-632.

61. Oakes J, Higgs D, Eales J, Devlin R (2007) Influence of ration level on the growth performance and body composition of non-transgenic and growthhormone-transgenic coho salmon (Oncorhynchus kisutch). Aquaculture 265 309-324.

62. Tibbetts S, Wall C, Barbosa-Solomieu V, Bryenton M, Plouffe D, et al. (2013) Effects of combined 'all-fish' growth hormone transgenics and triploidy on growth and nutrient utilization of Atlantic salmon (Salmo salar L.) fed a practical grower diet of known composition. Aquaculture 406: 141-152.

63. Leggatt R, Raven P, Mommsen T, Sakhrani D, Higgs D, et al. (2009) Growth hormone transgenesis influences carbohydrate, lipid and protein metabolism capacity for energy production in coho salmon (Oncorhynchus kisutch). Comp Biochem Physiol B 154: 121-133. 
Citation: Hixson SM (2014) Fish Nutrition and Current Issues in Aquaculture: The Balance in Providing Safe and Nutritious Seafood, in an Environmentally Sustainable Manner. J Aquac Res Development 5: 234 doi:10.4172/2155-9546.1000234

64. Xu Q, Feng C, Hori T, Plouffe D, Buchanan J, et al. (2013) Family-specific differences in growth rate and hepatic gene expression in juvenile triploid growth hormone $(\mathrm{GH})$ transgenic Atlantic salmon (Salmo salar). Comp Biochem Physiol D 8:317-333.

65. Rasmussen R, Morrissey M (2007) Biotechnology in aquaculture: transgenics and polyploidy. Comp Rev Food Sci 6: 2-16

66. Diana J, Egna H, Chopin T, Peterson M, Cao L, et al. (2013) Responsible aquaculture in 2050: valuing local conditions and human innovations will be key to success. Bioscience 63: 255-262.

67. Tacon A, Metian M (2013) Fish matters: Importance of aquatic foods in human nutrition and global food supply. Rev Fish Sci 21: 22-38.

68. Mansfield B (2012) Is fish health food or poison? Farmed fish and the material production of un/healthy nature. Antipode 43: 413-434.

69. Alvheim A, Torstensen B, Lin Y, Lillefosse H, Lock E, et al. (2013) Dietary linoleic acid elevates endogenous 2-arachidonolylglycerol and anandamide in Atlantic salmon (Salmo salar) and mice, and induces weight gain and inflammation in mice. Br J Nutr 109: 1508-1517.

70. Nichols P, Glencross B, Petrie J, Singh S (2014) Readily available sources of long-chain omega-3 oils: Is farmed Australian seafood a better source of the good oil than wild-caught seafood? Nutrients. 6: 1063-1079.

71. Raatz S, Rosenberger T, Johnson L, Wolters W, Burr G, et al. (2013) Dosedependent consumption of farmed Atlantic salmon (Salmo salar) increases plasma phospholipid n-3 fatty acids differentially. J Acad Nutr Diet 113: 282-287.

72. Torstensen B, Bell G, Rosenlund G, Henderson J, Graff I, et al. (2005) Tailoring of Atlantic salmon (Salmo salar) flesh lipid composition and sensory quality by replacing fish oil with a vegetable oil blend. J. Agric Food Chem 53: 1016610178

73. Rudd M, Pelletier N, Tyedmyers $P$ (2011) Preferences for health and environmental attributes of farmed salmon amongst southern Ontario salmon consumers. Aquacult Econ Manag 15: 18-45

74. Foran J, Hites R, Carpenter D, Hamilton C, Matthews-Amos A, et al. (2004) A survey of metals in tissues of farmed Atlantic and wild Pacific salmon. Environ Toxicol Chem 23: 2108-2110.

75. Waagbo R, Berntssen M, Danielsen T, Helberg H, Kleppa A, et al. (2013) Feeding Atlantic salmon diets with plant ingredients during the seawater phase - a full-scale net production of marine protein with focus on biological performance, welfare, product quality and safety. Aquacult Nutr 19:598-613.

76. Bell G, Dick J, Strachan F, Guy D, Bertssen M, et al. (2012) Complete replacement of fish oil with a blend of vegetable oils affects dioxin, dioxinlike polychlorinated biphenyls (PCBs) and polybrominated diphenyl ethers (PBDEs) in 3 Atlantic salmon (Salmo salar) families differing in flesh adiposity. Aquaculture 324: 118-126.

77. Friesen E, Ikonomou M, Higgs D, Ang K, Dubetz C (2008) Use of terrestria based lipids in aquaculture feeds and the effects on flesh organohalogen and fatty acid concentrations in farmed Atlantic salmon. Environ Sci Tech 42: 35193523.

78. Farrell A, Friesen E, Higgs D, Ikonomou M (2010) Toward improved public confidence in farmed fish quality: a Canadian perspective on the consequences of diet selection. J World Aqua Soc 41: 207-224.

79. Oliver J (2013) Food, water, soil, oil: Peak everything- Almost. In: Abstracts from Aquaculture Canada Conference, Guelph, Canada, June 1-4 2013.

80. Ahmadi P, Farahmanda H, Miandare H, Mirvaghefi A, Hoseinifar S (2014) The effects of dietary Immunogen ${ }^{\circledR}$ on innate immune response, immune related genes expression and disease resistance of rainbow trout (Oncorhynchus mykiss) Fish Shellfish Immunol 37:209-214.

81. Berge G, Hatlen B, Odom J, Ruyter B (2013) Physical treatment of high EPA Yarrowia lipolitica biomass increases the availability of $n-3$ highly unsaturated fatty acids when fed to Atlantic salmon. Aquacult Nutr 19: 110-121.
82. Chang C, Huang S, Chen S, Chen S (2013) Innate immune responses and efficacy of using mushroom beta-glucan mixture (MBG) on orange-spotted grouper, Epinephelus coioides, aquaculture. Fish Shellfish Immunol 35: 115125.

83. Crampton V, Carr I (2012) Fish Forever. In: Spotlight 5 EWOS publication. EWOS, Norway.

84. Dobsikova R, Blahova J, Mikulikova I, Modra H, Praskova E, et al. (2013) The effect of oyster mushroom $\beta$-1.3/1.6-D-glucan and oxytetracycline antibiotic on biometrical, haematological, biochemical, and immunological indices, and histopathological changes in common carp (Cyprinus carpio L.). J Fish Shellfish Immunol 35: 1813-1823.

85. Glencross B, Tocher D, Matthew C, Bell G (2014) Interactions between dietary docosahexaenoic acid and other long-chain polyunsaturated fatty acids on performance and fatty acid retention in post-smolt Atlantic salmon (Salmo salar). Fish Physiol Biochem DOI 10.1007/s10695-014-9917-8.

86. Guzman-Villanueva L, Ascencio-Valle F, Macias-Rodriguez M, Tovar-Ramirez D (2013) Effects of dietary $\beta-1,3 / 1,6$-glucan on the antioxidant and digestive enzyme activities of Pacific red snapper (Lutjanus peru) after exposure to lipopolysaccharides. Fish Physiol Biochem 10.1007/s10695-013-9889-0.

87. Kuhlwein H, Merrifield D, Rawling M, Foey A, Davies S (2014) Effects of dietary $\beta$-(1,3)(1,6)-D-glucan supplementation on growth performance, intestinal morphology and haemato-immunological profile of mirror carp (Cyprinus carpio L.). J Anim Physiol Anim Nutr 98: 279-289.

88. Lokesh J, Fernandes J, Korsnes K, Bergh O, Brinchmann M, et al. (2012) Transcriptional regulation of cytokines in the intestine of Atlantic cod fed yeast derived mannan oligosaccharide or $\beta$-Glucan and challenged with Vibrio anguillarum. Fish Shellfish Immunol 33: 626-631.

89. Morales-Lange B, Bethke J, Schmitt P, Mercado L (2014) Phenotypical parameters as a tool to evaluate the immunostimulatory effects of laminarin in Oncorhynchus mykiss. Aquacult. Res.

90. Poley J, Purcell S, Igboeli O, Donkin A, Wotton H, et al. (2013) Combinatoria effects of administration of immunostimulatory compounds in feed and followup administration of triple-dose SLICE $®$ (emamectin benzoate) on Atlantic salmon, Salmo salar L., infection with Lepeophtheirus salmonis. J Fish Dis 36: 299-309.

91. Rozita K, Shila S, Mahdy C (2013) Effect of whole and cell wall of Saccharomyces cervisiae in immunity factors on rainbow trout (Oncorhynchus mykiss). American-Eurasian J Agric Environ Sci 13: 633-638.

92. Sarker P, Bureau D, Hua K, Drew M, Forster I, et al. (2013) Sustainability issues related to feeding salmonids: a Canadian perspective. Rev Aqua 5: 1-21.

93. Syakuri H, Jung-Schroers V, Adamek M, Brogden G, Irnazarow I, et al (2014) Beta-glucan feeding differentiated the regulation of mRNA expression of claudin genes and prevented an intestinal inflammatory response post Aeromonas hydrophila intubation in common carp, Cyprinus carpio L. J. Fish Dis $37: 149-156$

94. Talpur A, Munir A, Mary A, Hashim R (2014) Aquaculture 426: 14-20.

95. WHO (World Health Organization) (1996) Rome Declaration on World Food Security and World Food Summit Plan of Action. Food and Agricultural Organization of the United Nations. 